\title{
The Approach of General Surgeons to Oncoplastic and Reconstructive Breast Surgery in Turkey: A Survey of Practice Patterns
}

\author{
Mustafa Emiroğlu ${ }^{1}$, İsmail Sert ${ }^{2}$, Abdullah İnal $^{3}$, Cem Karaali $^{1}$, Kemal Peker $^{3}$, Enver İlhan $^{4}$ \\ Mehmet Ali Gülçelik ${ }^{5}$, Varlık Erol ${ }^{1}$, Hilmi Güngör ${ }^{4}$, Didem Can ${ }^{6}$, Cengiz Aydın ${ }^{1}$ \\ ${ }^{1}$ Department of General Surgery, Tepecik Training and Research Hospital, İzmir, Turkey \\ ${ }^{2}$ Department of General Surgery, Van Regional Training and Research Hospital, Van, Turkey \\ ${ }^{3}$ Department of General Surgery, Erzincan University, Mengücek Gazi Training and Research Hospital, Erzincan, Turkey \\ ${ }^{4}$ Department of General Surgery, Bozyaka Training and Research Hospital, İzmir, Turkey \\ ${ }^{5}$ Department of General Surgery, Dr. Abdurrahman Yurtaslan Oncology Training and Research Hospital, Ankara, Turkey \\ ${ }^{6}$ Department of General Surgery, İstanbul Training and Research Hospital, İstanbul, Turkey
}

Background: Oncoplastic Breast Surgery (OBS), which is a combination of oncological procedures and plastic surgery techniques, has recently gained widespread use.

Aims: To assess the experiences, practice patterns and preferred approaches to Oncoplastic and Reconstructive Breast Surgery (ORBS) undertaken by general surgeons specializing in breast surgery in Turkey. Study Design: Cross-sectional study.

Methods: Between December 2013 and February 2014, an elevenquestion survey was distributed among 208 general surgeons specializing in breast surgery. The questions focused on the attitudes of general surgeons toward performing oncoplastic breast surgery (OBS), the role of the general surgeon in OBS and their training for it as well as their approaches to evaluating cosmetic outcomes in Breast Conserving Surgery (BCS) and informing patients about ORBS preoperatively.
Results: Responses from all 208 surgeons indicated that $79.8 \%$ evaluated the cosmetic outcomes of BCS, while $94.2 \%$ informed their patients preoperatively about ORBS. $52.5 \%$ performed BCS $(31.3 \%$ themselves, $21.1 \%$ together with a plastic surgeon). 53.8\% emphasized that general surgeons should carry out OBS themselves. $36.1 \%$ of respondents suggested that OBS training should be included within mainstream surgical training, whereas $27.4 \%$ believed this training should be conducted by specialised centres.

Conclusion: Although OBS procedure rates are low in Turkey, it is encouraging to see general surgeons practicing ORBS themselves. The survey demonstrates that our general surgeons aspire to learn and utilize OBS techniques.

Key Words: General surgeon, oncoplastic breast surgery, survey
With the wide acceptance of Fisher's theory that breast cancer is a systemic disease from the start and in the light of improvements in adjuvant treatment, the role of surgery in the treatment of cancer was expected to gradually decrease (1). However today's surgical treatment of breast cancer has developed into oncoplastic and reconstructive surgery (Oncoplastic Breast Surgery (OBS) + Reconstructive Breast Surgery $($ RBS $)=$ ORBS $)$. Besides establishing ideal regional oncological control, surgeons are often faced with the difficulties of conserving breast aesthetics or achieving optimal results. In a meta-analysis, Losken et al. reported that the rate of surgical margin involvement was $12.3 \%$ and $20.6 \%$ for patients who underwent OBS and Breast Conserving Surgery (BCS), respectively. In addition, they reported local recurrence rates of $3.6-4.7 \%$ and $7 \%$ for OBS and BCS, respectively (2). In another study comparing oncological outcomes for BCS and OBS, they reported tumour sizes of $17 \mathrm{~mm}$ and $24 \mathrm{~mm}$, surgical margins of $6 \mathrm{~mm}$ and $14 \mathrm{~mm}$, and rates of re-excision of $29 \%$ and $5.4 \%$, respectively. They suggested that OBS has a positive effect on oncological perspective in breast cancer surgery (3).

The Turkish Federation of Breast Disease Societies (TFBDS) made recommendations regarding ORBS at their first Breast Cancer Consensus Meeting in 2006 (4). In Tur-

This study was presented at the European Society of Musculoskeletal Radiology Congress, 28 May- 01 June, 2013, Istanbul, Turkey.

Address for Correspondence: Dr. Mustafa Emiroğlu, Department of General Surgery, Tepecik Training and Research Hospital, İzmir, Turkey Phone: +905052733254 e-mail: musemiroglu@gmail.com

Received: 24.03.2014 Accepted: 23.07.2014 Available Online Date: 22.10.2014 • DOI: 10.5152/balkanmedj.2014.13230

Available at www.balkanmedicaljournal.org 
key, there is no official Breast Surgery sub-specialization available to general surgeons. However, in certain teaching and research hospitals and university hospitals a small number of general surgeons do concentrate on breast surgery. Despite current publications and national guidelines, there is disparity in surgical approaches to ORBS. This is either due to limited resources in the workplace or the knowledge and experience of the individual surgeon.

Our study aims to investigate the experiences, applications and approaches to OBS and RBS taken by general surgeons who focus on breast surgery in Turkey. From our exploration of the available literature (Pubmed; Cohrane Database) we believe this to be a unique study, as it is the first survey of ORBS worldwide and in Turkey to involve such a large cohort of surgeons of this nature.

\section{MATERIAL AND METHODS}

Approval from the research ethics board at Tepecik Education and Research Hospital was obtained prior to starting this study. An online survey consisting of 11 questions entitled "Survey of Approaches to Oncoplastic and Reconstructive Breast Surgery" was sent by email together with a short explanatory cover note between December 2012 and January 2013 through the TFBDS website (Pleksus IT Inc.) to general surgeons focusing on breast surgery. The survey consisted of eleven questions (Table 1) that covered the following topics: demographics, clinical practice characteristics, and the use of PA in common breast surgical procedures. The survey was kept on the website for a further six weeks so additional surgeons could participate. After that, up until February 2013, volunteer surgeons used face-to-face interviews, telephone calls and direct emails to obtain completed questionnaires from surgeons in various parts of the country who had not already replied. The questions were developed in Turkish, but for the purpose of this publication they are provided in English.

The survey was designed by this publishing team. Seven of the eleven questions consisted of multiple-choice questions; the remaining 4 were also multiple-choice but included space for free-text comments. The survey comprised the following questions: the physician's institution; the number of new breast cancer operations carried out per year (number of operations); the ratio of BCS operations compared to the total number of breast surgeries (BCS ratio); whether patients were informed pre-operatively about ORBS and if so the rate of informing; whether aesthetic outcomes were evaluated at the early ( $0-1$ year) and late (3-5 years) stages and assessment methods used; whether they performed OBS and the meth-
TABLE 1. Characteristics of the participants

\begin{tabular}{lc}
\hline Characteristics & $\mathrm{n}(\%)$ \\
\hline Hospital & $84(40.4)$ \\
Research and Training Hospital & $62(29.8)$ \\
University Hospital & $35(16.8)$ \\
Private Hospital & $25(12.0)$ \\
State Hospital & $2(1.0)$ \\
Military Hospital & \\
The number of annual breast operations & $37(17.8)$ \\
$10-25$ & $61(29.3)$ \\
$25-40$ & $110(52.9)$ \\
$>40$ & \\
The percentage of BCS (\%) & $13(6.3)$ \\
$<10$ & $34(16.3)$ \\
$10-30$ & $70(33.7)$ \\
$30-50$ & $91(43.5)$ \\
$>50$ & \\
The percentage of OBS $(\%)$ & $73(35.1)$ \\
None & $59(28.1)$ \\
$<10$ & $57(27.4)$ \\
$10-30$ & $11(5.8)$ \\
$30-50$ & $7(3.4)$ \\
\hline $085: 0$ &
\end{tabular}

OBS: oncoplastic breast surgery; BCS: breast conserving surgery

ods used; the ratio of OBS compared to the total number of breast cancer surgeries (OBS ratio); whether reconstruction techniques were used in non-cancerous breast operations and the methods used; the role of the general surgeon in performing OBS; whether breast volume was measured or not and, if so, using which techniques; and opinions on the training and development of OBS.

All responses were anonymised; any duplication was eliminated. No incentives such as payment or gifts were offered to the participants. Participants who did not wish to contribute, whose questionnaire was only partially answered and/or who performed fewer than 10 breast cancer surgeries per year were excluded from the results. As all general surgeons in Turkey perform a wide range of operations other than breast surgery, we defined a general surgeon who specializes in or focuses on breast cancer surgery as one who undertook a minimum of ten cases per year of new breast cancer surgeries.

\section{Statistical analysis}

The data were analysed using Statistical Package for Social Sciences (SPSS) v.15 (SPSS Inc, Chicago, IL, USA). The results were classified by percentage distribution and descriptive statistics were given. 


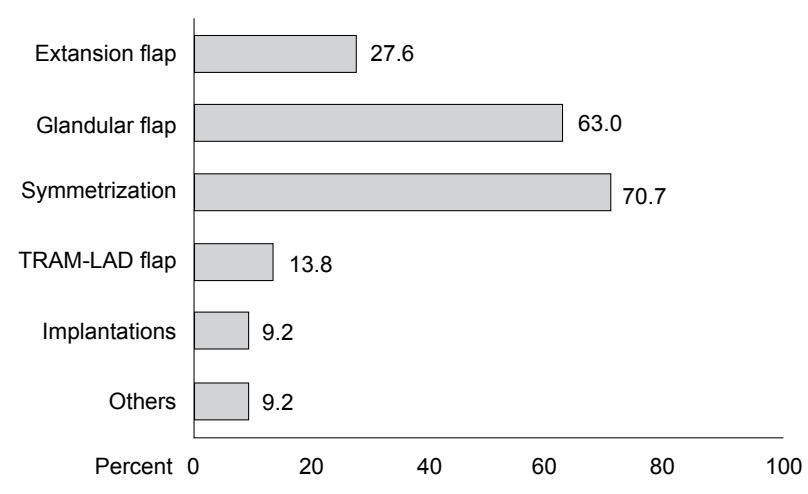

FIG. 1. Oncoplastic surgery techniques used by the surgeons

\section{RESULTS}

Surveys were sent to 249 General Surgeons. Forty-one were excluded from further analysis as the surveys were incomplete or the surgeons reported performing fewer than 10 breast cancer surgeries per year, leaving a total of 208. The surgeon's institution, total number of operations, ratios of BCS and OBS are summarized in Table 1. Nearly all surgeons (196: 94.2\%) reported informing the patient about ORBS prior to surgery. Of these, 101 (48.6\%) surgeons indicated "always", 66 (31.7\%) "sometimes", and 67 (13.9\%) "only if asked by the patient". In all, $166(79.8 \%)$ respondents assessed early (0-1 year) and late (3-5 years) stage cosmetic outcomes in breast cancer BCS. A total of 127 (61.1\%) respondents evaluated aesthetics according to patient satisfaction, 33 (11.2\%) surgeons used patient photographs and $16(7.7 \%)$ respondents employed a panel consisting of themselves, a radiation oncologist and a plastic surgeon.

When queried about performing OBS, $73(35 \%)$ respondents never implemented this operation, 44 (21.1\%) performed OBS together with a plastic surgeon in necessary cases, $26(12.5 \%)$ sent patients to plastic surgeons for late reconstruction and $65(31.3 \%)$ surgeons reported carrying out OBS themselves. Thus, a total of 109 (52.5\%) respondents actually performed OBS.

Of the 65 surgeons carrying out OBS by themselves, 46 (70.7\%) most frequently used the symmetrization technique (reduction and lifting of the breast). In the space left for free comments, 5 participants reported choosing a specific incision site and 1 described performing skin-sparing mastectomy. The OBS techniques preferred by the participants are shown in Figure 1.

A total of 68 (32.8\%) respondents reported using reconstructive breast surgery (RBS) in non-cancerous breast operations (such as macromastia, breast ptosis, large benign tumours, etc.) in order to achieve better aesthetic outcomes. A variety
TABLE 2. Training approaches for oncoplastic breast surgery

\begin{tabular}{lc}
\hline Opinions & $\mathrm{n}(\%)$ \\
\hline During the surgical training & $75(36.1)$ \\
By competent centres & $57(27.4)$ \\
By the Turkish Surgical Association & $51(24.5)$ \\
By the Ministry of Health & $13(6.3)$ \\
Surgeons should not perform OBS & $11(5.3)$ \\
\hline
\end{tabular}

OBS: oncoplastic breast surgery; BCS: breast conserving surgery

of RBS techniques were reported: of the 68 respondents, 45 (67.0\%) used symmetrization, 32 (47.1\%) used glandular flap, 13 (19.1\%) used extension flap, 3 (4.4\%) used Transverse Rectus Abdominis Myocutaneous (TRAM) flap and Latissimus Dorsi (LD) flap, while 3 (4.4\%) preferred implants. In the comments section of this question, 7 participants reported using specific incision sites.

When queried about the role of the general surgeon in OBS, $112(53.8 \%)$ respondents believed that surgeons should perform the surgery themselves if they were able, $39(18.8 \%)$ believed that all such procedures should be carried out together with a plastic surgeon, 37 (17.8\%) felt that a plastic surgeon's help should be enlisted when using a prosthesis, while 20 $(9.6 \%)$ believed that general surgeons should not perform OBS at all.

Table 2 shows approaches to training for OBS and expanding its use. In the free comments section of this question, 1 participant believed OBS should be regulated, 3 participants felt that cooperation with plastic surgeons was essential and 2 respondents emphasized the need for training opportunities for graduates.

A total of 48 (23.1\%) respondents reported measuring breast volume. Another 117 (56.3\%) said they did not measure breast volume but thought it would be useful. Forty-three (20.7\%) thought that measuring breast volume was unnecessary. The 48 surgeons used a variety of measurement techniques, with 28 (58.3\%) using the Grosman-Roudner device (GRD), 9 (18.8\%) using anatomic measurements, 9 (8.3\%) choosing a mammographic method, $4(6.3 \%)$ preferring casting, and $3(6.3 \%)$ using a water displacement technique. In the free comments section of this question, 2 participants reported additional use of a breast sizer (prosthetic measuring model).

\section{DISCUSSION}

The percentage of surgeons in our survey working towards better breast aesthetics in breast cancer surgery is satisfactory. The total number of simultaneous breast reconstructions was $52.5 \%$. In his study, Gwak reported that two-thirds of surgeons 
in South Korea performed breast reconstruction after mastectomy in early stage breast cancer patients (5). In his study in Turkey, Canturk researched disparities between 42 university hospitals in the diagnosis and surgical treatment of breast cancer. He found that OBS was used in $47.6 \%$ of participating hospitals (6). In a study conducted amongst general surgeons in Turkey, the number of surgeons utilizing OBS for breast cancer surgery was published as $48 \%$ (7). Morrow, at the 2013 St. Gallen consensus, emphasized that the use of intraoperative instruments such as an ultrasound probe allowed for tumour removal with acceptable safe boundaries. She considered that there was little place for procedures such as OBS in breast cancer surgery (8). Alternatively, it has been documented that, as the breast is an aesthetic organ, all operations should be oncoplastic (9). The average size ( $\mathrm{T}$ ) of initial breast cancers in Turkey has been reported as 2-5 cm (10), and OBS may be necessary to obtain good cosmetic outcomes for this $\mathrm{T}$ size. BCS has become a widely accepted procedure in Turkey over the past 10 years and the recognition and acceptance of OBS has only come in the wake of BCS becoming the norm. Although the rate of OBS operations is acceptable for our target group, we had expected it to be higher. We believe this is due to the lack of infrastructure in the workplace and the negative impact of our more traditional breast cancer surgical training.

According to our survey, the most frequent procedure used by general surgeons performing OBS without the help of a plastic surgeon is symmetrization. In South Korea, most surgeons are reported to prefer the use of surgical mesh and LD flap after BCS to reshape the local tissue (5). Bucimozza reports that the most common OBS procedure in South Africa is a volume replacement procedure (11). In India, performing LD flap together with BCS is the most preferred method of OBS (12). This marked difference between procedures in different countries is probably due to disparities in hospital infrastructure and the experiences of individual surgeons. $32.2 \%$ of our surgeons used RBS techniques in non-cancerous operations with symmetrization being the most popular procedure. Clearly, those using OBS methods in breast cancer make great use of the same techniques when conducting benign breast surgery.

Our study demonstrates that patients are sufficiently informed about ORBS by their surgeons. In England, $65 \%$ of patients undergoing mastectomy without reconstruction reported received the correct information, while $45 \%$ claimed they were not offered the choice of reconstruction (13). A survey conducted among general surgeons in Saudi Arabia reported that reconstruction was proposed for $36 \%$ of patients undergoing mastectomy for breast cancer (14). As ORBS can improve quality of life, it is clearly important to offer it to this kind of patient.
The uncertainty of our surgeons on the topic of OBS training became clear from our study. Important differences in OBS training between countries, institutions, doctors and patients were noted at the Senology Conference in Portugal in 2009 (15). In many countries OBS procedures vary tremendously $(3,15)$. In 2010, at a meeting of 11 OBS experts in the United Kingdom, surgical teamwork, institutional and individual practice work standards in Europe were discussed and defined (3). Surgeons are keen to learn and use OBS techniques. However, there are different opinions as to where and how this training should take place. We believe that the reality of the current situation in Turkey is far removed from the recommendations.

Our survey has clearly shown that, with regard to ORBS, general surgeons play the most dominant role. When we queried the role of the general surgeon in OBS, $53.8 \%$ of surgeons believed the general surgeon should carry out this procedure himself if able to, whereas $18 \%$ preferred to enlist the help of a plastic surgeon. The difficulties associated with breast diseases in countries with limited resources are well documented (16). The limited number of plastic surgeons in Turkey has contributed to a situation where general surgeons use and develop reconstructive techniques in their own procedures. In 2004, the first Macromastia and Breast Cancer Symposium and Course were held in Turkey and were run entirely by general surgeons (17). Again, in 2006, at the First National Breast Cancer Consensus Meeting, the oncoplastic surgery group was composed exclusively of general surgeons (4). In the Core Curriculum of General Surgery Residency Training published by the Turkish Surgery Association in 2006, residents were recommended to learn basic skills in breast reconstruction and cosmetic surgery techniques (18). We hope that these good intentions become a reality.

Our study revealed that aesthetic outcomes of BCS are assessed mainly by subjective methods in Turkey, where there is no gold standard as yet. Recommendations for both objective and subjective evaluations are currently being developed (19). The European Organization for Research and Treatment of Cancer (EORTC) supports a combination of qualitative and quantitative evaluations and suggests a panel with a minimum of five members for subjective evaluation (20). Although $79.8 \%$ of our respondents reported assessing aesthetic results, the quality of their evaluation was poor. As preserving breast aesthetics is an important reason for using BCS to treat breast cancer, evaluating cosmetic outcomes of BCS is undoubtedly essential. For appropriate aesthetic evaluation, validated test Breast Q should be used (21).

A large proportion of participants in the survey believe in the value of measuring breast volume. Reports underline the importance of breast volume measurement both in determin- 
ing the best ORBS technique and obtaining more objective assessments of post-surgery cosmetic outcomes (22). Mammographic methods, while expensive, are highly popular due to their accuracy and repeatability (23). However, the most widely used method seen in our study was GRD. It is a relatively popular method amongst surgeons in our country because it is cheap and easy to use.

Our findings should be interpreted in the context of some limitations. First, we may not have reached all surgeons in the target group, although we believe we reached a majority. Second, all results are based on self-reporting with no official verification and are approximate. Third, we have ignored the limitations of infrastructure and the trained workforce available to the respondents. Fourth, the stage of the breast cancer patients, adjuvant treatments, and multidisciplinary evaluation were not queried. Fifth, factors such as patient preferences and personal reasons when deciding on BCS, OBS, and RBS were not taken into consideration. Also, as our study results were descriptive, they may not have clarified different trends and our evaluations are limited to the questions asked. Finally, the views of all surgeons in the country may not be accurately portrayed in this study, as the respondent group was made up only of those surgeons who claimed to focus on breast surgery.

Despite these limitations, this survey does reflect the approaches to OBS and RBS taken by Turkish general surgeons who specialize in breast surgery, as the information was collected from all regions in the nation. As such, the survey offers an insight into its current status in our country. Although the percentage of OBS procedures undertaken in Turkey is insufficient, the extent of ORBS performed by general surgeons at their own initiative is encouraging. There is indecision about training and instruction for OBS. Initially, we must determine the actual problems and demands for OBS in Turkey. Then it must be decided how and by whom the organization and training will be accomplished. Also, the evaluation of cosmetic outcomes of BCS is high in quantity but low in quality. We believe that this survey can contribute to the expansion of OBS in Turkey and other developing countries. There is a need for national and international action to improve the application of ORBS and increase training for it.

Ethics Committee Approval: Ethics committee approval was received for this study from the local ethics committee.

Informed Consent: Written informed consent was obtained from patients who participated in this study.

Peer-review: Externally peer-reviewed.

Author contributions: Concept - M.E., I.S., A.I.; Design - M.I., A.I., I.S., M.G.; Supervision - M.E.; Data Collection\&/or Processing - M.E., I.S., A.I.,
C.K., K.P., E.I., M.G., V.E., H.G., D.C.; Analysis\&/or Interpretation -M.E., C.A.; Literature Search - M.E., C.K., I.S., A.I.; Writing - M.E., I.S., A.I.; Critical Reviews - M.E., M.G.

Conflict of Interest: No conflict of interest was declared by the authors.

Financial Disclosure: The authors declared that this study has received no financial support.

\section{REFERENCES}

1. Fisher B, Redmond C, Fisher ER, Bauer M, Wolmark N, Wickerham DL, et al. Ten years results of randomized clinical trial comparing radical mastectomy and total mastectomy with or without radiation. $N$ Engl J Med 1985;312:674-81. [CrossRef]

2. Losken A, Dugal CS, Styblo TM, Carlson. A meta-analysis comparing breast conservation therapy alone to the oncoplastic technique. Ann Plast Surg 2014;72:145-9. [CrossRef]

3. Down SK,Jha PK,Burger A,Hussien MI. Oncological advantages of oncoplastic breast-conserving surgery in treatment of early breast cancer. Breast J 2013; 19:56-63. [CrossRef]

4. Haydaroğlu A. 1. National Consensus of the Breast Cancer, İzmir: Congress printing office; 2007:63-8.

5. Gwack G, Lee HK, Kim HJ, Lee SY, Park YL, Lee JW. Survey of the application of the Korea clinical practice recommendations on Breast cancer treatment: Utility of the Korean Breast Cancer Society Guidelines. J Breast Cancer 2012;15:239-43. [CrossRef]

6. Cantürk NZ, Gulluoglu MB. Differences in breast cancer diagnosis and surgical treatment among Turkish Univeristy Hospitals. J Breast Health 2011;4:207-15.

7. Emiroğlu M, Inal A, Sert I, Ilhan E, Peker K, Gürçelik MA, et al. How do surgeons approach breast cancer surgery in Turkey? A national survey. Breast Cancer 2013 Oct 13. [Epub ahead of print] (DOI:10.1007/ s12282-013-0500-4)

8. Morrow M. 13 th St. Gallen IBCC; 2013.

9. Andree C, Farhadi J, Goossens D, Masia J, Sarfati I, Germann G, et al. A position statement on optimizing the role of oncoplastic breast surgery. E Plasty 2012;12:e40.

10. Tuncer M. Significance of cancer in Turkey, the burden of disease and cancer control policies. In: Tuncer M. Cancer control in Turkey. Ankara: Onur Press, Ministry of Health Publication; 2008:5-9.

11. Malycha PL, Gough IR, Margaritoni M, Deo SV, Sandalin K, Buccimazza I, et al. Oncoplastic breast surgery: A global perspective on practice, availability and training. World J Surg 2008;32:2570-7. [CrossRef]

12. Dixon JM, Venizelos B, Chan P. Latissimus dorsi miniflap: A technique for extending breast conservation. Breast 2002;11:58-65. [CrossRef]

13. National mastectomy and breast reconstruction oudit. 2010. Available from: http:// www.ic.nhs.uk/webfiles/services/NCASP/AUDITS\%20 and \%20 reports/whs \%20 IC\%20 MBR\%20 2010\%20 Audit\%20 interactive \%202024-06-10\%20 final.pdf.accessed.march1,2011.

14. Awan BA, Samargandi OA, Aldaqal SM, Alharbi AM, AlGhaithib Z. The attitude and perception of breast reconstruction by general surgeons in Saudi Arabia. Ann Saudi Med 2013;33:559-65.

15. Cardoso MJ, Macmillan RD, Merck B, Munhaz AM, Roibery R. Training in oncoplastic surgery: an international consensus. The 7th Portuquese senology congress, vilamoura, 2009. Breast 2010;19:538-40. [CrossRef]

16. Anderson BO, Braun S, Carlson RW, Gralow JR, Lagios MD, Lehman $\mathrm{C}$, et al. Overview of breast health care guidelines for countries with limited resources. Breast J 2003;9(Suppl) 2:S42-50. 
17. İzmir Society of Breast Disease. I. Symposium and Course of the Macromasty and Breast Cancer. 2004.

18. Residency training in general surgery; core cirruculum. Ankara: Turkish Surgical Association Press; 2006.

19. Cardoso MJ, Cardoso JS, Vrieling C, Macmillan D, Rainsbury D, Heil $\mathrm{J}$, et al. Recommendations for the aesthetic evaluation of breast cancer conservative treatment. Breast Cancer Res Treat 2012;135:629-37. [CrossRef]

20. EORTC BCC6 Manual for clinical research and treatment in breast cancer. 5th edition. London: Greenwich Medical Media; 2004.
21. Pusic AL, Klassen AF, Scott AM, Klok JA, Cordeiro PG, Cano SJ. Development of a new patient-reported outcome measure for breast surgery: the BREAST-Q. Plast Reconstr Surg 2009;124:345-53. [CrossRef]

22. Kovacs L, Eder M, Hollweck R, Zimmermann A, Settles M, Schneider A, et al. Comparison between breast volume measurment using 3D surface imaging and classical techniques. Breast 2007;16:137-45. [CrossRef]

23. Fung JT, Chan SW, Chiu AN, Cheung PS, Lam SH. Mamografic determination of breast volume by eliptical cone estimation. World J Surg 2010;34:142-5. [CrossRef] 